\title{
O PAPEL DO ESTADO E OS DESAFIOS DO PROFESSOR DE LITERATURA
}

Márcia Bassetto Paes

Resumo: Pensar sobre o lugar ocupado pela literatura no ensino brasileiro significa também avaliar sua posição e importância no currículo escolar. Para tanto o objetivo deste artigo é promover uma reflexão sobre o papel do Estado e os desafios enfrentados pelo professor de literatura, bem como os demais profissionais envolvidos com a Educação. Os parâmetros de sustentação para 0 desenvolvimento dos argumentos e para as considerações finais são os textos de Marilena Chauí, Escritos sobre a Universidade, e de Florestan Fernandes, Educação e Sociedade no Brasil.

Palavras-chave: autoritarismo, ensino, literatura, crítica social.

\section{THE ROLE OF THE STATE AND LITERATURE TEACHER CHALLENGES}

Abstract: To think about the place held by literature in Brazilian education is also to assess its place and value in the school curriculum. Therefore, this article aims at engaging in reflection about the role of the State and the challenges faced by Literature teachers, as well as by other professionals in the educational field. The supporting parameters for the elaboration of arguments and of the final considerations are the texts Escritos sobre a Universidade [Writings on the University], by Marilena Chauí, and Educação e Sociedade no Brasil [Education and Society in Brazil], by Florestan Fernandes.

Keywords: authoritarianism, education, literature, social criticism. 


\section{Introdução}

A escolha da discussão aborda o levantamento de alguns, dentre tantos, problemas enfrentados pelos docentes de literatura, bem como sua agenda de reivindicações e a relação direta com as políticas do Estado. Nesta perspectiva, é possível traçar uma rota onde se evidenciam as seguintes questões: 1) quais os caminhos trilhados pela literatura e o ensino de literatura no Brasil? 2) quais as políticas aprovadas, na esfera governamental, em relação ao ensino de literatura e seus principais propósitos; 3) quem é o aluno destinatário do ensino de literatura e qual a finalidade na formação de leitores?; 4) qual a formação do professor responsável por esse ensino que não se identifica como produtor de conhecimento?; 5) qual o conteúdo e como é feita sua escolha - a questão dos manuais didáticos -, e qual seria o tratamento apropriado para o texto literário?

Ao organizar essa sequência de questionamentos, é evidente a constatação de duas vertentes de discussão aparentemente dissociadas. Uma delas trata da estrutura de educação estabelecida no país e a outra diz respeito ao conteúdo, a maneira de transmiti-lo e o impacto na formação do estudante. A importância de sublinhar a aparente desconexão entre estas pontas vem no sentido de adotar uma estrutura de educação não excludente; ou seja, estabelecida no âmbito da democracia social fundada na compreensão do social "como divisão interna das classes a partir da exploração econômica e, portanto, como luta de classes", conforme entendimento de Marilena Chauí (CHAUÍ, 2005, p. 23). Desde esse ponto de vista, a abordagem deveria, necessariamente, apontar para um conteúdo literário polissêmico, que seja apresentado de várias maneiras e interpretado através de várias visões. Também ganha relevância o papel auxiliar na organização do entendimento do aluno a partir de seu lugar social, sob pena de não alcançar a meta final, isto é, a formação deste indivíduo.

É fácil perceber ambiguidades estabelecidas, sobretudo após a transição da ditadura civil militar para o restabelecimento do Estado de Direito, e a constituição de 1988. Ouve-se falar, muito frequentemente, da escola pública "de antigamente" com um tom de nostalgia e acompanhado da expressão "o tempo em que a escola pública era boa". Tempo esse cujo ingresso no ensino fundamental se dava através de um "exame de admissão" - portanto os alunos, cujas famílias podiam pagar, faziam um ano de aulas de "admissão" -, era ensinado latim no Ensino Médio e, 
nos departamentos das faculdades de humanas, professores desembarcados da Europa ministravam aulas em francês. Evidentemente esse modelo de escola pública, extremamente excludente e voltado para a classe média urbana mais abastada, há muito não encontra mais lugar. Do outro lado está a massificação do ensino público, iniciada no governo militar, e continuada desde a gestão de Fernando Henrique Cardoso. O desenvolvimento da reflexão vem no sentido de descartar estas duas hipóteses.

\section{A herança da Educação Brasileira}

A herança da estrutura da Educação brasileira vem de uma matriz extremamente autoritária e violenta, iniciada pelos jesuítas, cujos métodos de catequese não pouparam o derramamento de sangue para o estabelecimento da doutrina católica. A sociedade de então, essencialmente agrária e escravista, se desenvolvia lentamente com escassas possibilidades de trabalho livre e sem lugar para a instrução e cultura, "exceção feita pela obra catequética que se encerra dentro de seus próprios limites" (COSTA, 1999, p. 274). A educação básica era desprovida de função para a população livre marginalizada já que, ao contrário da Coroa espanhola, a "Coroa portuguesa preferiu reservar à metrópole o monopólio do ensino superior, não chegando a fundar nenhuma Universidade na colônia portuguesa durante o período colonial" (COSTA, 1999, p. 275). Assim, os colégios religiosos tiveram o monopólio da cultura, preenchendo as necessidades básicas da matriz, fornecendo uma educação onde a literatura era estudada como retórica, da gramática ao latim, erudita, ornamental, e definidora de status e elitista pela própria natureza. Este caráter ornamental, definidor de status e elitista nasce na monarquia, se estende pelas duas Repúblicas e coopta representantes de setores não ligados à oligarquia, como mestiços e negros livres que conseguiam penetrar no misterioso mundo das letras - fato que começa a ocorrer em fins do séc. XIX. Negros e mestiços alfabetizados se deslocavam espiritualmente, aos olhos da elite e aos próprios olhos. Era como que a "literatura branqueasse essa gente", na concepção de Antonio Risério, em artigo para a Revista da USP (RISÉRIO, 1993, p. 183). O autor resgata, no mesmo artigo, uma observação de Roger Bastide a propósito de Silva Alvarenga: "se falasse com demasiada simplicidade, talvez as más línguas denunciassem traços da herança materna em seus versos". Poderia, portanto, haver uma proximidade na classificação social de quem sabia "falar 
difícil", por parte daqueles destituídos favorecidos pelo letramento. Sem dúvida é corriqueiro, ainda, o uso pretensioso da linguagem e o lustro da erudição forjada no cânone europeu como símbolo de status.

Outras mudanças ocorrem a partir da segunda metade do século XIX, momento em que a erudição clássica sai de cena e dá lugar as obras cujos autores colaboram com a construção de elementos definidores de uma concepção de nação. Sob o jugo da política cultural do Império, o Instituto Histórico Geográfico Brasileiro (IHGB) constituiu o chão fértil para os ideais de nação e de Estado e foi a seara onde os intelectuais e formadores de opinião propõem "o 'esclarecimento' da sociedade, pelo desenvolvimento da 'cultura literária', levando a um aprimoramento das relações sociais”. O Instituto, segundo Manuel Luiz Salgado Guimarães, tinha o propósito de "dar conta da gênese da Nação brasileira, inserindo-a, contudo, numa tradição de civilização e progresso, ideias referenciadas no iluminismo" (GUIMARÃES, 2002, 184).

Em 1891, José Veríssimo, autor de A Educação Nacional, envolvido nas discussões sobre o que deveria ser o ensino brasileiro, propõe a reforma do livro de leitura:

Neste levantamento geral que é preciso promover a favor da educação nacional, uma das mais necessárias reformas é a do livro de leitura. Cumpre que elle seja brazileiro, não só feito por brazileiro, que não é o mais importante, mas brazileiro pelos assumptos, pelo espirito, pelos autores trasladados, pelos poetas reproduzidos e pelo sentimento nacional que 0 anime. (VERÍSSIMO, 1906, p.79).

É essa visão de literatura e cultura que se estabelece no Estado Novo e desenha o modelo de escola pública. Com o Estado Novo a geração de Gilberto Freyre foi surpreendida por um processo de rápidas mudanças. É forjada uma nova geração de intelectuais, produto da Universidade de São Paulo, e de outras instituições análogas, "criadas nos anos 30 com a finalidade de formar a nova elite de profissionais e burocratas relativamente independentes das oligarquias tradicionais" (COSTA, 1999, p. 383). O crescimento das novas usinas, substitutas dos engenhos de açúcar, fez surgir outro problema social: a classe operária. Com estas mudanças, o operariado e a classe média - formados por imigrantes e resultantes do processo de industrialização e inchamento urbano -, pressionam por ofertas de ensino, qualificação técnica e uma reforma educacional que dê conta da 
falta de escolas e do baixo rendimento do sistema escolar. Com os olhos voltados para a conquista do apoio do trabalhador urbano, base política de Getúlio Vargas, a reforma adotada deixa de fora um grande contingente de pessoas provindas do trabalho na zona rural.

Para Antonio Candido, até esse período "o principal meio de que o Brasil dispunha para conhecer-se a si mesmo era a literatura". Segundo o crítico, a história, a geografia e a filosofia, eram pensadas por intermédio desta arte da palavra que detinha um papel fundador na cultura nacional (CANDIDO, 2000). $\mathrm{Na}$ mesma linha, Alfredo Bosi afirma que "no Brasil o projeto de integração da literatura na história nacional foi abrangente e fecundo [...] e que o historicismo nacionalista é uma criação romântica, e no seu cerne já se contém o historicismo sociológico que o século XX herdou do positivismo e do evolucionismo" (BOSI, 2000, p. 12).

Hans Robert Jauss, ao escrever sobre o mesmo período, sustenta que a disciplina de história da literatura estava no auge nas escolas alemãs e era o caminho a se apresentar a ideia de nação e individualidade nacional, buscada pela intelectualidade do país como chancela do processo de unificação (HAUSS, 1994).

\section{A Educação durante os anos de Ditadura Civil Militar}

No Brasil, após o golpe de 1964, os ditadores armados de políticas colaboracionistas e de apoio ao governo americano, ajudaram a deteriorar este cenário através de medidas de massificação. O eixo central da política adotada pelo Ministério da Educação e Cultura e ditada pela caserna com a conivência de representações civis, foi no sentido de estabelecer uma série de acordos e convênios de assistência técnica e cooperação financeira à educação brasileira com a United States Agency for International Development (USAID). Os acordos feitos entre todos os níveis escolares - da educação básica ao ensino superior -, estabeleciam o fornecimento de diretrizes para uma reorientação do sistema educacional brasileiro, à luz das necessidades do mercado internacional (CUNHA, 2002). A missão de técnicos norte-americanos, trazidos para cá, consistia em adequar o sistema de ensino aos interesses das corporações norte-americanas. Os doze documentos assinados, o último em 1976, foram decisivos para adequar as escolas a um tecnicismo educacional.

Esta situação inspira o professor Florestan Fernandes a elaborar, no calor da hora, em 1966, um importante texto que examina esta situação. Embora ainda não 
totalmente afetado pela entrega da política educacional aos americanos, são apontados alguns problemas que irão perdurar até hoje sem perspectiva de solução. O professor questiona o papel da Faculdade de Filosofia Letras e Ciências Humanas da Universidade de São Paulo (FFLCH/USP) na melhora da estrutura do sistema escolar e cobra a existência de professores bem formados e "competentes para o ensino secundário". Ressalta que "as falhas apontadas não foram corrigidas por falta de planejamento global realístico, eficiente e produtivo" (FERNANDES, $A$ crise do ensino, p. 118) e que o "Governo poderia ter tomado iniciativas, que hoje não serão recebidas sem conflitos (grifo meu), no plano da constituição da Universidade" (Idem, p. 119).

Florestan elenca alguns males, frutos de intervenções parciais e localizadas sem "uma clara visão das dimensões sociais dos problemas humanos", que podem ser assim alinhadas: 1) introdução de um sistema básico de ensino comum e de entrosamento das atividades de ensino ou pesquisa com o objetivo de eliminar gastos inúteis; dar assistência material e moral adequada aos alunos; garantir rigorosa seleção de candidatos aos quadros de ensino. 2) desistência de uma vida universitária real que não seja mero aglomerado de instituições de ensino superior. 3) o professor secundário submetido a condições obsoletas de trabalho didático, sem suficiente prática no ensino de suas matérias. 4) plano de estudos e de ideais de vida intelectual sofreram violento abalo diante das condições salariais e obrigações de trabalho impostas. 5) conflito entre integridade intelectual do professor versus uma nova concepção de direitos e deveres do professor e seus técnicos administrativos; chefes políticos, representantes de igrejas, e, ainda, pais de alunos cuja compreensão do papel da escola é limitado. 6) ambições pedagógicas nobres e legítimas foram espezinhadas e extenuadas, no contato de condições impróprias de relações entre professor e aluno. Enfim, para Florestan Fernandes “'o mau aluno' não existe, pois ele é produzido pela 'má escola' e pelo 'mau ensino"' (idem, p. 120).

Convidada a refletir sobre a situação do ensino e da pesquisa em humanidades, a professora Marilena Chauí, no artigo O mal-estar na universidade: o caso das humanidades e das ciências sociais, vinte e oito anos mais tarde, converge com os pontos levantados por Florestan Fernandes. 


\section{A inessencialidade do ensino de humanas}

Chauí, ao examinar como foi produzida a inessencialidade do ensino de humanas, enumera três etapas. A primeira, entre 1964 e 1974, está no campo do perigo subversivo. O ensino de literatura se torna inessencial ao projeto de 'integrar a nação' à modernidade capitalista. Modernização esta que incluía "como um dos momentos principais, a destruição da escola pública de primeiro e segundo graus". A segunda, entre 1974 e 1975, o ensino de literatura é percebido como inessencial no projeto do milagre brasileiro, isto é, o desmantelamento do ensino público de primeiro e segundo graus concomitante à política de ampliação da rede de escolas privadas e a expansão das escolas profissionalizantes. $O$ ensino passa a ser um problema de mercado e, para seu êxito, é executada uma reforma curricular simplificadora das áreas de humanas com o objetivo de formar o professor no menor tempo possível. Adotam-se aí as licenciaturas curtas. É o momento, também, onde a promiscuidade do ensino com os interesses do capital, muitas vezes travestido em organizações não governamentais e fundações, ganha terreno principalmente em relação às pesquisas. A terceira contempla o período a partir de 1985. Nesse momento, é decretada a inessencialidade das disciplinas de humanas através de duas vertentes. Uma delas é a dos excluídos, ou voluntariamente saídos da universidade que, através de padrões de trabalho de seus institutos e centros privados, declaram a falência universitária e das disciplinas da área identificadas como "improdutivas, corporativas, rotineiras, irrelevantes". Simultaneamente, a ideologia neoliberal condena o investimento do Estado em pesquisas no âmbito acadêmico, pois as mesmas - sob esta ótica - não constituem interesse público. Assim nasce o conceito de que o bom pesquisador é aquele vinculado ao mundo corporativo.

Para Chauí, a expressão "socialismo ou barbárie" é uma síntese dotada de sentido, e não um slogan. "A salvação modernizante consiste em levar a ideia e a prática da privatização do público às últimas consequências [...], pois não serão definidos pelos pesquisadores, mas pelos 'mecenas'". Ao professor de literatura resta juntar energias para provar que o ensino das humanidades para a formação intelectual dos seres humanos é essencial, por mais paradoxal que a formulação possa parecer. 


\section{A Educação após a abertura}

Após o lento processo de abertura, iniciado com as mobilizações estudantis de 1977, continuado pelo movimento Diretas Já e que culminou na aprovação da Constituinte em 1988, o tema Educação timidamente entra para a agenda nacional. Durante os anos 1995 e 1996 dá-se início a um processo de discussão resultando em uma publicação oficial dos primeiros parâmetros curriculares, referente ao ensino fundamental. Em 1997, Paulo Renato de Souza, ministro do então presidente Fernando Henrique Cardoso, despachou para as escolas os Parâmetros Curriculares Nacionais (PCN). Em 1999, foram lançados os Parâmetros Curriculares Nacionais para o Ensino Médio (PCNEM). Assim são criados referenciais cujos propósitos eram "a renovação e reelaboração da proposta curricular" que é de "inegável importância para a política educacional da nação" (MEC, 1997, p. 9 e 14).

Paralelo aos PCNs surgiu o Plano Nacional do Livro Didático (PNLD), em primeira instância atendendo ao Ensino Fundamental e a partir de 2005, já sob o governo de Luis Inácio Lula da Silva, em caráter experimental, foram distribuídos livros de português e matemática aos alunos de 1ํ․ ano do Ensino Médio das regiões Norte e Nordeste. Segundo o portal do Fundo Nacional do

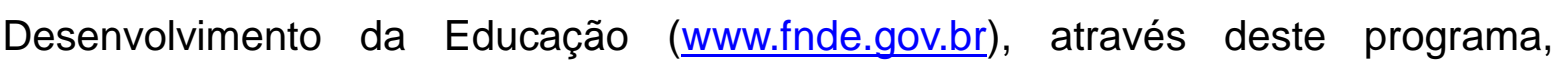
mantido com recursos do Orçamento Geral da União e pelo programa de melhoria de expansão do Ensino Médio, o governo se propôs a avaliar os livros didáticos inscritos pelas editoras, a produzir um guia com a relação dos livros aprovados e a distribuir estes guias às escolas públicas. Dessa forma os professores escolhem os livros com os quais gostariam de trabalhar, comprar e distribuir para os alunos da rede pública.

Tais políticas, PNLD e PCNs, mostram a preocupação por parte do MEC em cumprir o papel que the cabe quanto à educação, ao oferecer uma gama de alternativas metodológicas e didáticas para o professor escolher. No entanto, fica a dúvida até que ponto esse professor está preparado para as mudanças impostas a eles.

Uma característica marcante dos programas é o papel dispensado ao Ensino Médio que deixa de ser preparatório para o ensino superior e passa a ter um caráter de formação geral do cidadão crítico. A disciplina literatura teve seu 
conteúdo diluído nos ensinos de língua portuguesa e artes e esta, por sua vez, passa a fazer parte de uma área genérica batizada de "Linguagens, Códigos e suas Tecnologias". A orientação pressupunha o entendimento de que a disciplina não deveria ser pautada pela história da literatura, mas sim por uma "estética da sensibilidade" integrada à área de leitura. No entanto, em entrevista concedida ao jornal Folha de S.Paulo em 04 de dezembro de 2000, o ministro Paulo Renato de Souza vem a explicitar que "quando definimos os PCN, achávamos que eles iriam impactar as escolas imediatamente. Depois nos demos conta, em reuniões com secretários, que os parâmetros não estavam sendo assimilados pelos professores. Tivemos que lançar os Parâmetros em Ação, que explicavam melhor como desenvolvê-los na prática".

Assim, a literatura passa a ser incluída como competência a ser desenvolvida na disciplina Língua Portuguesa com o objetivo de "identificar manifestações no eixo temporal, reconhecendo os momentos de tradição e ruptura" e ainda sugeriam "o estudo das obras clássicas de nossa literatura" mas enfatizava que o objetivo da disciplina no Ensino Médio deveria ser a "formação de leitores e não de identificadores de escolas literárias, com seus respectivos autores e estilos". Estas orientações, no entanto, não coincidiam com o edital de inscrição para o Programa Nacional do Livro Didático, segundo o qual "a tradicional concepção informativa de literatura, entendida como conjunto de conhecimentos histórico-culturais e estéticos que se supõem poder fazer a mediação entre leitor e obra [...] considera-se excessivamente normativa e canônica perturbando o efetivo trabalho do leitor" (MEC, 2003, p. 29-31).

Criado o impasse, diante das contradições das propostas elaboradas pelo governo de Fernando Henrique Cardoso em confronto com os editais do governo de Luís Inácio Lula da Silva, em julho de 2006, no portal MEC/FNDE, são publicadas as Orientações Curriculares Nacionais para o Ensino Médio (OCNEM). Trata-se de um documento específico para a disciplina de Literatura cuja proposta principal para a sala de aula é a leitura integral da obra literária:

As Orientações colocam em questão a formação do aluno, enquanto leitor, a partir da defesa da qualidade estética da obra. $O$ documento destaca que:

[...] o texto escolhido, seja ele popular ou erudito, deve ser levado em consideração as mesmas questões impostas a um texto canônico: Há intencionalidade artística?; A realização 
correspondeu à intenção?; quais os recursos utilizados para tal?; qual o seu significado histórico-social? Proporciona o texto o estranhamento, o prazer estético? (MEC, 2006, p. 57).

A publicação do MEC suscita, ainda, atenção quando alavanca conceitos elaborados por Umberto Eco ao identificar dois tipos básicos de leitor. Um 'leitor vítima' interessado no conteúdo do texto e o 'leitor crítico' preocupado com o "como" a história é contada: "O primeiro é a vítima, designada pelas próprias estratégias enunciativas, o segundo é o leitor crítico, que ri do modo pelo qual foi levado a ser vítima designada" (Eco, 1989, apud MEC, 2006, p. 68).

A questão, portanto, é como fornecer condições para que os alunos possam se tornar leitores críticos. E, por conseguinte, que tipo de leitor é o sujeito responsável por fornecer estas condições? Trata-se de transmitir um determinado conteúdo literário ou ensinar um modo de ler um texto literário?

\section{O Ensino de Literatura e os impasses criados após 2002}

Partindo-se da constatação de que a maioria dos adolescentes, quando muito, carrega como únicas referências as leituras de aventuras como Harry Poter, Crônicas de Nárnia, entre outros de mesmo teor, que integram um circuito de cinema, internet, televisão e jogos, não é difícil a constatação de que a obrigatoriedade da leitura de obras constantes nos currículos de Ensino Médio passa a ser uma atividade enfadonha e forçada. A situação torna-se mais calamitosa ao examinarmos a situação de impotência em que se encontra a grande maioria dos professores de língua portuguesa para chegar a um objetivo a contento, tanto pela formação precária, quanto pela falta de atualização didática e pedagógica para o ensino de literatura.

O que espanta é que o discurso de Marilena Chauí e o de Florestan Fernandes, este escrito em plena ditadura e o outro em um momento de voo democrático, elaborados com quase trinta anos de distância entre um e outro, não diferem em suas essências e não são estranhos, tampouco, da situação em que se encontra o ensino de literatura hoje, em meio a primeira década do século XXI. Esse raciocínio leva o observador atento a concluir que o ensino de literatura se encontra ameaçado e submetido a concepções autoritárias independente do regime, seja aquele governado com a mão de ferro de ditadores ou este cujas políticas estão resguardadas pelos direitos democráticos. 
Há quarenta e oito anos de distância dos problemas apontados por Florestan Fernandes em $A$ crise do ensino e vinte anos cravados desde a palestra de Marilena Chauí, os problemas permanecem sem solução. $O$ ensino de literatura ministrado nos ciclos Fundamental e Médio, baseado em manuais didáticos, é apresentado com simplificações, resumos, personagens estereotipados e reverberam clichês de interpretações consagradas no século passado. O objetivo evidente não é a dotação de debate e atitude crítica. Trata-se tão somente de outorgar um diploma.

Por outro lado, os professores de literatura, também oriundos deste sistema onde a crítica não é contemplada e seu papel, na engrenagem de um mundo construído pela ideologia neoliberal, é absolutamente descartável, só encontram desmotivação e elementos que corroboram com a deterioração da autoestima.

Nas várias greves das redes públicas de ensino - com destaque para São Paulo - levadas por estudantes, professores e funcionários das Universidades Estaduais e, na cidade de São Paulo, os professores da rede municipal -, tais questões não fazem parte de nenhuma das pautas de reivindicações.

O novo Plano Nacional de Educação, aprovado dia 05 de junho de 2014 após tramitar por várias instâncias desde 2011, considera os investimentos em programas como PROUNI e PRONATEC como sendo investimentos no ensino público. Argumento que é contraditório com a defesa dos $10 \%$ do PIB para educação pública. Daí a retirada do termo "público" do texto documento final aprovado.

Outra questão a ser observada é relativa à polêmica sobre a manutenção ou exclusão do artigo que delega à educação a busca da "superação das desigualdades educacionais, com ênfase na promoção de igualdade racial, regional, de gênero e de orientação sexual", levantada pela bancada evangélica que considerou esse artigo como uma imposição do "marxismo cultural" e da "ideologia de gênero" e conseguiu barrar a proposta na comissão. Em consequência, a redação foi alterada para "a erradicação de todas as formas de discriminação". Estes são apenas alguns impasses impostos ao governo de coalizão do Partido dos Trabalhadores.

A presidenta Dilma Rousseff, em pronunciamento no rádio e na TV no dia 01 de maio de 2014, anunciou o envio ao Congresso Nacional de uma nova proposta 
determinando que todos os royalties do petróleo e recursos do pré-sal sejam aplicados exclusivamente na educação. "O Brasil precisa de uma grande revolução no ensino capaz de garantir o nosso futuro como nação líder e soberana no mundo", afirmou a presidenta que concluiu com o slogan "Brasil, pátria educadora". Porém não surtiram efeito as mobilizações, encabeçadas pelas entidades ligadas aos setores de ensino e a vontade de fazer uma revolução no ensino, se a pauta é destituída da séria reflexão sobre a situação do ensino no Brasil. Talvez este seja o quarto momento da inessencialidade: somos inessenciais até para aqueles cujas bandeiras reivindicatórias outrora reclamavam o reconhecimento da essencialidade.

Florestan Fernandes inicia seus argumentos declarando-se um otimista, no entanto finaliza evocando Erasmo e tece algumas considerações acerca da loucura. Para ele "na escola [...] aprende-se, isso sim, a aliviar a consciência, a encurtar o caminho, a atingir os fins pelos meios mais rápidos, a escolher uma carreira sem desejá-la e sem pretender honrá-la. Essa é a pior das loucuras [...] filha do 'progresso' e matriz da 'civilização'” (FERNANDES, 1966, p.120).

Chauí, ao contrário do professor, se alinha aos pessimistas e alerta para 0 perigo de confundir "a modernização com a aceitação passiva do que o capitalismo impõe" e também "a crítica do presente com a nostalgia do passado".

Das considerações possíveis, decorre a necessidade de uma mobilização constante em torno dos problemas do ensino. Problemas estes germinados com o saque das reservas de pau-brasil e que se agravaram e se sofisticaram de tal maneira até sumir das pautas de reivindicações.

Trata-se de acreditar na transformação do ensino de literatura até chegar a se constituir em um elemento motivador para a elaboração e reflexão de problemas complexos e em perspectiva crítica. Trata-se, também, de investir no potencial de formação intelectual que o ensino de literatura encerra, ao propiciar reflexões que adentram a outras áreas do saber, como história, antropologia, política e economia. Enfim, é urgente a adoção de tal perspectiva, sob pena de sermos arrebatados para uma dimensão patética, como o professor de $A$ lista de Schindler, citado por Chauí, por não perceber que o mundo foi dominado pela barbárie nazista; ou, ainda, cair na rede da loucura moderna, sublime, refinada e pervertida que "não guarda mais parentesco com 'a natureza dos homens'”. 


\section{Referências bibliográficas}

CANDIDO, Antonio. Formação da Literatura Brasileira. Rio de Janeiro: Itatiaia, 2000.

CHAUÍ, M. S. "Considerações sobre a democracia e os obstáculos à sua concretização". In: Os sentidos da democracia e da participação. Org.: TEIXEIRA, Ana Paula. Centro de Documentação e de Informação do Instituto Pólis. São Paulo: Pólis Publicação, 2005, v. 47.

CHAUÍ, M. S. O mal-estar na universidade: o caso das humanidades e das ciências sociais. In: Escritos sobre a universidade. São Paulo: Editora UNESP, 2001.

COSTA, Emília Viotti da. Da monarquia à república: momentos decisivos. São Paulo: Editora da Unesp, 1998.

CUNHA, Luiz Antonio e GÓES, Moacyr de. O golpe na educação. 11 1 a edição. Rio de Janeiro: Zahar Editora, 2002.

Discursos da Presidenta. www2.planalto.gov.br/acompanhe-oplanalto/discursos/discursos-da-presidenta. Acesso: 02/junho/2014.

FERNANDES, Florestan. A Educação na sociedade Brasileira. In: Educação e Sociedade no Brasil. São Paulo: Dominus/EDUSP, 1966.

GUIMARÃES, Manuel Luiz Salgado. Entre o amadorismo e o profissionalismo: as tensões da prática histórica no século XIX. Topoi: Rio de Janeiro, 2002. pp. 184 -200 .

JAUSS, Hans Robert. A história da literatura como provocação à teoria literária. São Paulo: Ática, 1994.

MINISTÉRIO DA EDUCAÇÃO/CNE. Diretrizes Curriculares Nacionais para o Ensino Médio (DCNEM). In: PCNEM, Brasil, MEC/SEMTEC. Brasília, 1999.

MINISTÉRIO DA EDUCAÇÃO/SEB. Orientações Curriculares Nacionais (Ensino Médio). Literatura. Ministério da Educação/SEMTEC. Brasília, 2006.

MINISTÉRIO DA EDUCAÇÃO/SEF. Parâmetros Curriculares Nacionais (Terceiro e Quarto Ciclos do Ensino Fundamental). Língua Portuguesa. Ministério da Educação/SEMTEC. Brasília, 1997. 
. Parâmetros Curriculares Nacionais + Ensino Médio. Orientações Educacionais aos PCN. Brasília, 2002.

. Edital de Convocação do Programa Nacional do Livro Didático do Ensino Médio/2005. Brasília: 2006.

MINISTÉRIO DA EDUCAÇÃO E CULTURA/FNDE/SEMTEC. (2003) Edital de convocação para a inscrição de livros didáticos no processo de avaliação e seleção de obras a serem incluídas no catálogo de escolha de livros da 1ạ. a 3ạ. séries do Programa Nacional do livro para o Ensino Médio - PNLEM/2005. Disponível em: www.fnde.gov.br. Acesso em dez/20014.

RISÉRIO, Antonio. Blackout. A exclusão do texto africano. In: Dossiê Brasil/África. Revista da USP N. 18. São Paulo: Coordenadoria de Comunicação e Cultura da USP, 1993.

VERÍSSIMO, José. A Educação Nacional, Rio de Janeiro: Livraria Francisco Alves, 1906). 